\title{
Uma Análise do Capital Humano Sobre o Nível de Renda dos Estados Brasileiros: MRW Versus Mincer
}

\author{
- Ricardo Corrêa Cangussu* Márcio Antônio Salvato**

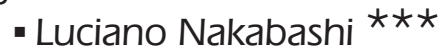

\begin{abstract}
Resumo
O capital humano, a produtividade e o capital físico são considerados os principais fatores na determinação do PIB per capita das economias. Conforme a abordagem neoclássica, a acumulação de capital humano explica praticamente um terço da variação do rendimento per capita entre os países. No entanto, ainda persistem discussões sobre as formas em que esse fator afeta o PIB per capita. O objetivo do presente estudo é comparar duas formas funcionais da função de produção para os Estados brasileiros: as propostas por Solow (1956) e por Mincer (1974). Também foram feitas estimações do retorno marginal da educação, além da realização de uma análise da importância do capital humano na determinação do PIB per capita utilizando diferentes métodos de estimação, no período 1980-2002. Os resultados rejeitaram a especificação neoclássica com inclusão do capital humano em favor da minceriana. Adicionalmente, o retorno marginal estimado da educação foi de $15 \%$, e os resultados empíricos sustentam a teoria de que o capital humano é um dos principais fatores na determinação do nível de renda.
\end{abstract}

\section{Palavras-Chave}

capital humano, crescimento econômico, função de produção minceriana, retorno da educação

\begin{abstract}
Human capital, productivity and physical capital are considered the main factors in the economies' GDP per capita determination. According to the neoclassical approach, human capital accumulation explains about a third of the variation in per capita income across countries. However, there is no consensus on the ways in which human capital influences GDP per capita. The present study's goal is to compare two production functions functional forms for the Brazilian States: the one developed by Solow (1956) and the one developed by Mincer (1974). The marginal return of education also has been estimated and we have analyzed the relevance of human capital on GDP per capita determination through a variety of estimation methods, for the 1980-2002 period. The empirical results rejected the neoclassical specification with human capital in favor of the mincerian's specification. The estimated marginal return of education is $15 \%$ and the empirical findings support the theory that states that human capital is one of the main factors affecting income level.
\end{abstract}

\section{Keywords}

human capital, economic growth, mincerian production function, return of education

\section{JEL Classification}

$\mathrm{C} 13, \mathrm{C} 23, \mathrm{O} 11, \mathrm{O} 41$

\footnotetext{
* Economista pela PUC-MG. Endereço para contato: R. Juca Flávio, 346 - Contagem - MG. CEP: 32223280. E-mail: correarc@hotmail.com.

** Doutor em Economia pela EPGE-FGV/RJ. Professor do IBMEC-MG. E-mail: marcio.salvato@gmail.com.

$\star \star \star$ Doutor em economia, professor do Departamento de Economia da UFPR e coordenador do boletim de Economia \& Tecnologia. Endereço para contato: Av Prefeito Lothário Meissner, 632 - térreo. Departamento de Economia - Jardim Botânico, Curitiba - PR. CEP: 80210-170. E-mail: luciano.nakabashi@ufpr.br.

(Recebido em fevereiro de 2008. Aceito para publicação em maio de 2009).
} 


\section{Introdução}

O capital humano é um fator de produção que ganha cada vez mais importância na explicação do diferencial de renda entre os países, seja na literatura teórica ou empírica. Teoricamente, o capital humano é importante na determinação da renda por vias diretas e indiretas. Os efeitos diretos do capital humano são aqueles que afetam a renda através da melhora na produtividade marginal do trabalho, mantendo todos os outros fatores constantes (capital e tecnologia), isto é, da melhora na habilidade dos trabalhadores para a realização de suas respectivas tarefas. Ele é representado pela introdução do capital humano de forma direta na função de produção. Esse efeito foi enfatizado, inicialmente, por Schultz (1962) e incorporado em modelos como o de Mankiw, Romer e Weil (1992).

O efeito direto ressalta a importância dos fatores de produção (capitais físico e humano) na explicação do diferencial de renda entre os países (object gaps), enquanto alguns outros autores ressaltam a importância no diferencial de produtividade (idea gaps), como Romer (1993), Klenow e Rodríguez-Clare (1997) e Easterly e Levine (2001). No entanto, o presente estudo apresenta evidências de que o capital humano afeta o diferencial de renda através dos seus efeitos diretos e indiretos. Ou seja, a questão não é simplesmente entre acumulação de fatores de produção, de um lado, e produtividade, do outro, pois existe uma correlação positiva entre os fatores de produção e a produtividade. Essa correlação se deve, pelo menos em parte, aos efeitos indiretos do capital humano sobre a renda.

Os efeitos indiretos são aqueles que afetam a quantidade de tecnologia disponível para ser utilizada no processo de produção. Assim, são os fatores que influenciam a criação e difusão de tecnologia. A importância do capital humano na geração de tecnologia é enfatizada por Lucas (1988), Romer (1990a) e Aghion e Howitt (1992). No que diz respeito ao processo de difusão, o artigo seminal é o de Nelson e Phelps (1966). Aplicações empíricas desse modelo e extensões dele foram feitas por Benhabib e Spiegel (1994 e 2002), por exemplo.

Apesar de alguns estudos macroeconômicos não encontrarem uma relação entre o capital humano e nível de renda e/ou crescimento econômico, como por exemplo, Pritchett (2001) e Romer (1990b), existem várias justificativas para tais resultados, sendo três mais relevantes.

A primeira é a utilização de uma forma funcional equivocada para mensurar a relação entre as variáveis (TEMPLE, 1999). Um exemplo é a análise de Benhabib e Spiegel (1994), onde os autores desenvolvem um modelo teórico com base nos estudos de Nelson e Phelps (op. cit.) e Romer (1990a), ma qual o capital humano é 
relevante na determinação da produtividade total dos fatores via inovação e difusão. Alguns autores ainda consideram a relevância das interações entre importações e capital humano no processo de difusão, como Coe e Helpman (1995), Coe, Helpman e Hoffmaister (1997), Keller (1999) e Connolly (2003). Outros estudos mostram que as interações entre capital humano e investimento estrangeiro direto (IED) podem ser cruciais no processo de difusão, como Javorcik (2004), Xu (2000) e Borensztein et al. (1998). Nakabashi e Figueiredo (2008) desenvolvem um modelo formal que inclui esses diferentes canais para analisar o impacto do capital humano sobre o crescimento econômico para uma série de diferentes países.

Outra possibilidade de mudança na forma funcional são estudos que incluem retornos crescentes e decrescentes de escala na produção de capital humano, como é o caso de Trostel (2004). O autor mostra que a produção de capital humano apresenta retornos crescentes de escala em regiões com baixa quantidade de capital humano, enquanto os retornos são decrescentes em regiões com elevado nível de capital humano.

A segunda é a inadequação da proxy utilizada para mensurar a quantidade de capital humano. Islam (1995) sugere que a baixa qualidade das proxies para capital humano, quando se adiciona a dimensão temporal na análise, faz com que a relação positiva entre elas e a renda se dissipe. Além do problema da qualidade do capital humano, que não é levada em consideração na maior parte dos estudos empíricos, ocorre um problema na mensuração da quantidade desse fator quando se comparam países muito diferentes. Krueger e Lindahl (2001) mostram que existem sérios problemas em algumas bases de dados que mensuram a quantidade de capital humano para vários países através do tempo, como a de Kyriacou (1991) e Barro e Lee (1993).

Finalmente, em muitas análises empíricas não se utiliza o método apropriado para a estimação do modelo teórico. Um caso típico é a não consideração da relação de bicausalidade ou causalidade reversa entre capital humano e renda, como enfatizado por Bonelli (2002), ou simplesmente a consideração de que a variável proxy para capital humano seja endógena no problema, tornando a estimação por mínimos quadrados viesada e inconsistente (CRAVO, 2006). Assim, em análises empíricas, deve-se testar a endogeneidade das variáveis.

O presente estudo foca o primeiro e o terceiro dos problemas mencionados. Como o objeto de análise é apenas um país, espera-se que o diferencial de qualidade entre as unidades de análise seja menor do que em estudos que realizam comparações internacionais. Adicionalmente, quando não se considera o fator qualidade, ocorre uma queda na correlação entre renda e nível de capital humano, como enfatizado 
por Islam (op. cit.) e Sachs e Warner (1997). Como, no presente estudo, se encontra uma correlação positiva entre as variáveis, a inclusão da qualidade faria com que os resultados fossem mais pronunciados.

A escolha de especificação do modelo é feita de acordo com o estudo realizado por Ferreira, Issler e Pessôa (2004), comparando as especificações da função de produção de Mankiw, Romer e Weil (op. cit.) e Mincer (op. cit.) para os Estados brasileiros, no período 1980-2002. Cabe ressaltar que essa utilização da equação minceriana em estudos macroeconômicos já tinha sido testada em alguns estudos anteriores para vários países, como é o caso de Krueger e Lindahl (op. cit.). Desse modo, no presente estudo é feita uma análise dos impactos diretos do capital humano sobre a renda dos Estados brasileiros de acordo com as duas especificações acima mencionadas.

Para proceder a tal análise comparativa de especificação da função de produção, uma variedade de métodos econométricos é utilizada com o intuito de trabalhar as principais críticas no uso de dados em painel. Além das tradicionais estimações por Mínimos Quadrados Ordinários (OLS), por Mínimos Quadrados com Variável Dummy (LSDV) e Mínimos Quadrados Generalizados (GLS), foram considerados estimadores de dois estágios com o uso de variáveis instrumentais com o intuito de considerar problemas de endogeneidade. Além disso, na presença de amostra reduzida para informações da série de tempo e variáveis explicativas não exógenas, a literatura recomenda o uso dos estimadores de Arellano e Bond (1991) e Arellano e Bover (1995), desenvolvido por Blundell e Bond (1998), usando o algoritmo descrito por Roodman (2006) para painel dinâmico.

Os resultados da análise empírica, assim como no estudo realizado por Ferreira, Issler e Pessôa (op. cit.), favorecem a especificação minceriana em relação ao modelo de crescimento neoclássico ampliado, ou seja, o de Mankiw, Romer e Weil (op. cit.).

Além dessa introdução, o presente artigo está organizado da seguinte forma: na seção 2 é feita uma breve apresentação dos estudos empíricos para o caso brasileiro; na próxima é feita uma breve apresentação dos modelos teóricos que servem de base para o estudo empírico; na seção 4 são apresentadas a metodologia e as fontes dos dados; e, na última, os resultados empíricos são mostrados e comentados. 


\section{O Capital Humano nos Estudos Empíricos para o Brasil}

A análise econômica empírica dos Estados brasileiros está mais focada na discussão sobre distribuição de renda e convergência. Uma boa razão para explicar essa tendência é o nível de desigualdade entre as regiões. Alguns desses estudos fazem o uso do fator capital humano como uma variável de controle, mas a análise desse fator na explicação do nível e taxa de crescimento da renda está longe de ser a preocupação central. Normalmente, os estudos empíricos encontram evidência que dão sustentação à hipótese de existência de convergência absoluta da renda per capita nos Estados do Brasil, como em Ferreira (1996) e Azzoni (2001). Entretanto, como ressaltado por Azzoni (ibidem), com uma grande variação na evolução da desigualdade de renda através do tempo e de regiões.

Quando alguma outra variável é incluída como controle ocorre um aumento na velocidade de convergência (condicional), e o coeficiente da proxy para capital humano, quando essa variável é incluída na análise, é positivo e significativo. Os resultados encontrados por Azzoni et al. (1999) mostram que o nível da renda per capita dos Estados brasileiros está positivamente correlacionado com o nível de capital humano. O nível de renda também tem uma correlação positiva com variáveis geográficas, por exemplo.

Alguns outros estudos que examinam o efeito do capital humano sobre o nível e/ou taxa de crescimento da renda per capita dos Estados brasileiros são Ferreira (2000), Andrade (1997), e Lau et al. (1993).

A principal preocupação de Ferreira (op. cit.) é a mensuração da velocidade de convergência entre os Estados. Porém, seus resultados mostram que capital humano é um fator relevante na explicação da taxa de crescimento da renda nos Estados brasileiros.

Os resultados de Lau et al. (op. cit.) indicam que, em média, um ano adicional de escolaridade dos trabalhadores do Brasil tem um impacto positivo sobre a renda de, aproximadamente, $20 \%$. Portanto, a média dos anos de estudo dos trabalhadores brasileiros tem um papel fundamental na determinação do nível de renda dos Estados. Andrade (op. cit.) encontra um impacto ainda maior do capital humano sobre o nível de renda: um ano adicional de escolaridade da população em idade de trabalhar aumenta o PIB em torno de $32 \%$.

Nakabashi e Salvato (2007) incorporam, na análise empírica, uma proxy para a qualidade do capital humano. Os resultados indicam que apesar de o impacto direto do capital humano no nível de renda e na taxa de crescimento dos Estados brasileiros 
ser menor em relação aos resultados que empregam uma proxy meramente quantitativa, a sua significância aumenta.

Em relação à especificação do modelo, podemos ressaltar o trabalho de Dias, Dias e Lima (2009) que analisam uma relação não linear entre capital humano e crescimento econômico para os estados brasileiros. Os resultados desse estudo indicam que a relação entre as duas variáveis é não linear na forma de U invertido. Outro esforço no sentido da mudança de especificação foi feito por Nakabashi e Figueiredo (op. cit.). Os autores desenvolvem um modelo que leva em consideração tanto os impactos diretos quanto indiretos do capital humano sobre o crescimento da renda per capita. Os resultados indicam que o capital humano atua, principalmente, na difusão de tecnologia.

Outro ponto relevante que vem sendo analisado na literatura é a importância da distribuição de capital humano entre os agentes econômicos. Por exemplo, em um estudo para os Estados brasileiros Dias e Dias (2007) apresentam evidências de que uma elevação do capital humano dos empregados em relação aos empregadores tem um efeito positivo sobre a taxa de crescimento da produtividade nos Estados.

No entanto, alguns estudos indicam que o capital humano pode não ser tão relevante sobre o nível e/ou crescimento da renda per capita. Os resultados da análise de Portugal e Souza (1999), que se concentra nos estados da região sul, indicam que o impacto do capital humano sobre o crescimento econômico só é relevante para o Rio Grande do Sul. Dias e Dias (op. cit.) mostram, ainda, que investimentos em educação podem ter efeitos negativos sobre a produtividade, pelo menos no curto prazo, devido à realocação de fatores do setor produtivo para o setor de acumulação do capital humano, podendo inibir maiores investimentos em educação.

\section{Capital Humano nos Modelos de Determinação da Renda}

\subsection{Especificação de Mankiw, Romer e Weil (op. cit.)}

Mankiw, Romer e Weil (op. cit. $)^{1}$ argumentam que a exclusão do capital humano no modelo de crescimento original de Solow-Swan, Solow (op. cit.) e Swan (1956), pode potencializar as estimativas da influência da poupança e do crescimento populacional na renda per capita devido à correlação existente entre estas e a primeira. Ao ampliarem o modelo de Solow-Swan, MRW incluem o fator capital humano na função de produção:

1 MRW doravante. 


$$
Y_{t}=K_{t}^{\alpha} H_{t}^{\beta}\left(A_{t} L_{t}\right)^{1-\alpha-\beta}
$$

em que $Y$ é o produto, $K$ o capital, $L$ o trabalho, $A$ o termo tecnológico, $t$ é o tempo e $\alpha, \beta$ e $(1-\alpha-\beta)$ referem-se às participações do capital físico, humano e trabalho na renda, respectivamente. De acordo com a equação (1), a tecnologia é poupadora de trabalho e, desse modo, esse fator em unidades efetivas de trabalho, $A_{t} L_{t}$, cresce a uma taxa $n+g$, em que $n$ é a taxa de crescimento populacional e $g$ a taxa de crescimento da tecnologia:

$$
\begin{aligned}
& L_{t}=L(0) e^{n t} \\
& A_{t}=A(0) e^{g t}
\end{aligned}
$$

Definindo que o produto e o estoque de capital físico e humano na equação (1) sejam expressos em unidades efetivas de trabalho, temos: $\hat{y}=\frac{Y}{A L} ; \hat{k}=\frac{K}{A L}$; e $\hat{h}=\frac{H}{A L}$. Adicionalmente, considerando que tanto capital físico quanto o humano depreciam-se à mesma taxa $\delta$, temos as equações que definem $k \mathrm{e} h$, em termos de crescimento:

$$
\begin{aligned}
& \dot{k}_{t}=s_{k} y_{t}-(n+g+\delta) k_{t} \\
& \dot{h}_{t}=s_{h} y_{t}-(n+g+\delta) h_{t}
\end{aligned}
$$

em que $s_{k}$ representa a fração da renda investida em capital físico, $s_{h}$ a fração da renda investida em capital humano e os outros termos são aqueles já definidos anteriormente.

No estado estacionário, as equações (4a) e (4b) se igualam a zero, formando um sistema de duas equações e duas variáveis endógenas: as quantidades de capital humano e físico por unidades de trabalho. Resolvendo para estas variáveis, têm-se:

$$
k^{*}=\left(\frac{s_{k}^{1-\beta} s_{h}^{\beta}}{n+g+\delta}\right)^{1 /(1-\alpha-\beta)}
$$




$$
h^{*}=\left(\frac{s_{k}^{\alpha} s_{h}^{1-\alpha}}{n+g+\delta}\right)^{1 /(1-\alpha-\beta)}
$$

em que o subscrito * denota que a variável se encontra no estado estacionário. Substituindo as equações (5a) e (5b) na função de produção expressa em unidades de trabalho $\left(\hat{y}=\hat{k}^{\alpha} \hat{h}^{\beta}\right)$ e transformando ambos os lados da equação em logaritmo natural, chega-se à equação em termos de produto por trabalhador:

$$
\begin{aligned}
& \ln y^{*}=\ln A(0)+g t-\frac{\alpha+\beta}{1-\alpha-\beta} \ln (n+g+\delta)+\frac{\alpha}{1-\alpha-\beta} \ln \left(s_{k}\right) \\
& +\frac{\beta}{1-\alpha-\beta} \ln \left(s_{h}\right)
\end{aligned}
$$

Nesta equação, o termo $g t$ representa a taxa de progresso tecnológico. O termo $A(0)$, por sua vez, reflete a dotação de fatores, tais como instituições, nível de estabilidade política, respeito às liberdades individuais, entre outros. Sendo assim, esse termo pode variar entre as economias. MRW assumem que:

$$
\ln A_{t}=a+\varepsilon
$$

em que $a$ é uma constante e $\varepsilon$ representa a especificidade de cada país. A equação acima será utilizada para a estimação das produtividades estaduais.

Substituindo (7) em (6), encontra-se:

$$
\begin{aligned}
& \ln \left(y^{*}\right)=a+g t+\left(\frac{\alpha}{1-\alpha-\beta}\right) \ln \left(s_{k}\right)+\left(\frac{\beta}{1-\alpha-\beta}\right) \ln \left(s_{h}\right) \\
& -\left(\frac{\alpha+\beta}{1-\alpha-\beta}\right) \ln (n+g+\delta)+\varepsilon
\end{aligned}
$$

A equação (8) representa a variação da renda per capita no estado estacionário e será utilizada para as regressões das economias cuja renda encontre-se nesse estado.

Os autores sugerem que essa nova formulação responde por cerca de $80 \%$ da variação da renda per capita entre os países. Adicionalmente, eles encontram evidências de que o capital humano é um fator de extrema relevância para explicar o diferencial de renda e de crescimento entre os países. 


\subsection{Especificação de Mincer (op. cit.)}

Outros autores, no entanto, testaram a função de produção minceriana. Essa especificação, na qual o capital humano é introduzido na função de produção na forma exponencial, foi confrontada recentemente por Ferreira, Issler e Pessôa (op. cit.) com o modelo usado por MRW, em que o capital humano é expresso em nível.

Originalmente, a equação minceriana foi desenvolvida para realização de análises que utilizam dados microeconômicos como, por exemplo, os estudos realizados por Bils e Klenow (2000), Hall e Jones (1999) e Klenow e Rodríguez-Clare (op. cit.). No entanto, Ferreira, Issler e Pessôa (op. cit.) mostraram que essa especificação também é apropriada em análises macroeconômicas.

Nessa especificação, o capital humano é introduzido na função de produção na forma exponencial:

$$
Y=A K^{\alpha}(\exp (\varphi h) L \exp (g \cdot t))^{\beta}
$$

O parâmetro $\exp (\varphi h)$ pode ser entendido como a percentagem do aumento na renda decorrente de um ano adicional de escolaridade. As demais variáveis e parâmetros têm o mesmo significado proposto anteriormente.

Segundo Ferreira, Issler e Pessoa (ibidem), "assume-se que o nível de habilidade de um trabalhador com $h$ anos de escolaridade é $\exp (\varphi h)$ mais elevado do que um trabalhador sem qualquer instrução" (tradução nossa). ${ }^{2}$

Definindo a equação (9) em unidades efetivas de trabalho e aplicando-se logaritmo natural, chega-se à equação (10), a qual será objeto de estimação:

$$
\ln y^{*}=\ln A+\alpha \ln k+(1-\alpha)(\varphi h+g \cdot t)+\varepsilon
$$

Como sugere Ferreira, Issler e Pessoa (ibidem),

Econometricamente, a diferença básica entre as equações (8) e (10) é se o capital humano entra na função de produção em nível ou em log. Se o capital humano entrar em logs - (8), há uma elasticidade fixa do capital humano na produção dos estados. Se

2 It is assumed that the skill level of a worker with h years of schooling is exp(øh) greater than that of a worker with no education at all. 
este entra em nível - (10), a elasticidade do capital humano na produção mudará entre os estados e através do tempo também. (tradução nossa). ${ }^{3}$

Ferreira, Issler e Pessoa (ibidem), por intermédio do teste Box-Cox, rejeitaram a especificação de MRW em favor da especificação minceriana. Utilizando um painel de dados de 95 países em vários estágios de desenvolvimento entre 1960 e 1985, os autores encontraram uma estimativa para o retorno marginal da educação de 7,5\% por ano e crescimento estimado da produtividade de 1,4\% por ano.

\section{Metodologia}

\subsection{Considerações sobre as Estimações ${ }^{4}$}

Antes da definição do melhor método a ser estimado e da melhor formulação para a função de produção, foram realizados alguns testes econométricos com o intuito de identificar possíveis problemas que resultassem em estimativas tendenciosas e inconsistentes dos parâmetros.

Foram realizados testes para detectar problemas de multicolinearidade, heterocedasticidade e autocorrelação. Para a detecção da multicolinearidade foi utilizado o Fator Inflação de Variância (FIV). Para testar a hipótese nula de homocedasticidade dos resíduos foi utilizado o teste de Breusch-Pagan. Para a detecção de autocorrelação, o teste utilizado foi o proposto por Arellano e Bond, sob a hipótese nula de que não há autocorrelação de primeira ordem no painel.

O método de Cochrane-Orcutt a partir da transformação de Prais-Winsten foi utilizado para corrigir problemas de autocorrelação e heterocedasticidade. Como observa Greene (2001), a transformação Prais-Winsten remove a autocorrelação e a heterocedasticidade presentes nos dados.

Outros seis diferentes métodos de estimação foram aplicados neste trabalho. O primeiro é "pooled regression", que utiliza Mínimos Quadrados Ordinários (MQO) para estimação dos dados. A escolha deste método - também utilizado por MRW -

3 Econometrically, the basic difference between equations (8) and (10) is whether human capital enters the production function in levels or in logs. If human capital enters in logs - (8), there is a fixed human-capital elasticity in production for all countries. If it enters in levels - (10), humancapital elasticity in production will change across countries (and across time as well).

4 Todos os testes e as regressões apresentadas foram feitas através do pacote econométrico STATA 8.0 . 
possui algumas limitações: a possível correlação entre o termo de erro e pelo menos uma das variáveis independentes.

O segundo método é o de dados de painel, que pode ser de efeitos fixos - Mínimos Quadrados com Variável Dummy ${ }^{5}$ ou de efeitos aleatórios. A utilização do primeiro método permite que as diferenças entre os indivíduos possam ser capturadas nas diferenças do termo constante. O segundo é estimado a partir de Mínimos Quadrados Generalizados (MQG) ${ }^{6}$, incorporando os efeitos individuais no termo de erro.

Hausman (1978) desenvolveu um teste para a definição do método de estimação mais eficiente quando se compara o de efeitos fixos e o de efeitos aleatórios. Sob a hipótese nula, o método mais adequado a ser empregado é o de efeitos aleatórios, enquanto a hipótese alternativa favorece o método de efeitos fixos. O teste é baseado na diferença dos estimadores dos diferentes métodos de estimação.

O passo seguinte foi testar a endogeneidade das variáveis. Davidson e Mackinnon (1993) recomendam o teste de Durbin-Wu-Hausman para a detecção da endogeneidade. Caso esse problema seja constatado, Hausman (1983) sugere o uso de variáveis defasadas como variáveis instrumentais. Hall e Jones (op. cit.) sugerem o uso da latitude. Barro e Lee (op. cit.), Barro e Sala-I-Martin (1995) e Ferreira, Issler e Pessôa (op. cit.) são exemplos de trabalhos que consideram métodos de estimação que utilizam variáveis instrumentais.

Durlauf et al. (2004) afirmam que algumas das alternativas mais utilizadas para a correção da endogeneidade são o uso do método Mínimos Quadrados em Dois Estágios (MQ2E) e do Método dos Momentos Generalizados (MMG).

Além das variáveis exógenas, os seguintes instrumentos foram utilizados: os valores defasados até a terceira defasagem das proxies para capital físico e capital humano e o valor absoluto da latitude em graus dividido por $90 .{ }^{7}$ Adicionalmente, optouse por estimar as equações através do método de MQ2E por ser mais amplo que o MMG.

O quarto método de estimação utilizado foi o de efeitos fixos com a inclusão de variáveis instrumentais. O quinto refere-se à regressão por efeitos aleatórios utilizando variáveis instrumentais, a partir da estimação por Mínimos Quadrados Generalizados em Dois Estágios (MQG2E).

5 Least Square Dummy Variable - LSDV.

6 Generalized Least Square - GLS.

7 Este procedimento é similar ao proposto por Hall e Jones (op. cit.) e tem por objetivo condicionar a latitude em uma escala de 0 a 1. 
O passo seguinte foi testar a validade dos instrumentos utilizados nos modelos estruturais. Ferreira, Issler e Pessôa (op. cit.) recomendam o uso do teste de Sargan para essa verificação. Esse teste consiste em estimar regressões auxiliares utilizando os resíduos das variáveis instrumentais e construir uma estatística $\mathrm{T} \times \mathrm{R}^{2}$ com os resultados da regressão auxiliar. Ainda que este procedimento seja útil para testar a "ortogonalidade" de cada equação do sistema, é útil também para testar a correta especificação do modelo $^{8}$ (FERREIRA; ISSLER; PESSÔA, op. cit.).

O quinto método econométrico sugerido é a utilização da estimação de painel dinâmico usando os estimadores de Arellano e Bond (1991) e Arellano e Bover (1995) e desenvolvido por Blundell e Bond (op. cit.). Roodman (op. cit.), descrevendo os métodos, argumenta que tais estimadores são apropriados no uso de dados em painel quando temos: i) poucos períodos de tempo e muitos indivíduos; ii) relação funcional linear; iii) variável dependente com coeficiente autorregressivo; iv) variáveis explicativas não estritamente exógenas; v) efeito fixo para indivíduos e vi) erros não cilíndricos. ${ }^{9}$ O estimador Arellano-Bond usa as variáveis em diferença e o método generalizado dos momentos de Hansen (1982) para estimar os parâmetros e por isso é conhecido como "difference GMM". O estimador Arellano-Bover/BlundellBond é equivalente ao estimador Arellano-Bond incluindo uma hipótese adicional: a primeira diferença dos instrumentos é não correlacionada com os efeitos fixos, o que permite aumentar o número de instrumentos e ganhar em eficiência. Este segundo estimador é conhecido como "system GMM".

Para testar a hipótese se o capital humano entra na função de produção em nível ou em log utilizou-se o teste Box-Cox, como sugerido por Aguirre (1997).

Considere a equação genérica da regressão, usando a transformação Box-Cox para o regressor:

$$
\begin{aligned}
& y_{t}=\left(\frac{x_{t}^{\theta}-1}{\theta}\right) \beta+\varepsilon_{t} \\
& \lim _{\theta \rightarrow 0}\left(\frac{x_{t}^{\theta}-1}{\theta}\right)=\ln \left(x_{t}\right)
\end{aligned}
$$

8 Em outras palavras, a rejeição da hipótese nula indica que os instrumentos utilizados não são válidos.

9 Presença de heterocedasticidade e autocorrelação dentro dos grupos de indivíduos, mas não entre os grupos. 


$$
\lim _{\theta \rightarrow 1}\left(\frac{x_{t}^{\theta}-1}{\theta}\right)=x_{t}-1
$$

na qual fica claro que, para uma transformação logarítmica ser válida, deveremos ter $\theta=0$, e para que $x_{\mathrm{t}}$ entre na regressão em nível, devemos ter $\theta=1$. Essas duas hipóteses podem ser testadas por meio do teste de Wald, usando a transformação Box-Cox para a medida do capital humano na função de produção.

\subsection{Base de Dados}

A base de dados utilizada é formada por 25 das 27 Unidades Federativas do Brasil ${ }^{10}$ e compreende o período 1980-2002. Os dados foram obtidos a partir do endereço eletrônico do Instituto de Pesquisa Econômica Aplicada (IPEA).

As variáveis utilizadas foram: 1) Produto Interno Bruto (PIB) per capita a preços constantes - R\$ de 2000, deflacionados pelo deflator implícito do PIB nacional; 2) população residente, sendo que a taxa de crescimento da população residente é mensurada pela taxa de variação das estimativas das populações residentes segundo as unidades da federação: 1980 - 2002; 3) consumo de energia elétrica industrial como proxy para capital físico, sendo medido em mega-watts-hora; e 4) anos de estudo das pessoas com 25 anos e mais, como proxy para capital humano.

Nos modelos de estimação em dois estágios, os instrumentos para as variáveis endógenas utilizados foram: 3 defasadas das endógenas e a variável latitude da unidade federativa, além das variáveis exógenas da equação (crescimento populacional e ano)

\section{Análise Empírica}

\subsection{Análise Inicial dos Dados}

A análise da Tabela 1 permite observar que as diferenças no nível de produto per capita entre os Estados brasileiros são bastante acentuadas, estando de acordo com os resultados apresentados por Azzoni (2001).

10 Os Estados de Goiás e Tocantins ficaram de fora da amostra. O Estado de Goiás foi dividido em dois (Goiás e Tocantins) em 1988 e, por esse motivo, não foi possível gerar uma série contínua para estes Estados. 
Cabe destacar alguns números apresentados nessa tabela. Por exemplo, o PIB per capita do Piauí era apenas 10\% do PIB per capita do Distrito Federal, em 1980. Após 22 anos, o cenário não sofreu mudanças significativas; em 2002 passou para 13\%. Alguns Estados conseguiram diminuir o diferencial de renda consideravelmente, como Paraíba, Ceará, Rio Grande do Norte e Sergipe. No entanto, ele continua muito elevado.

Tabela 1 - Disparidades no Indicador de Crescimento Econômico: 1980-2002

\begin{tabular}{lccccccc}
\hline Unidade Federativa & $y_{i}(1980)^{\mathrm{a}}$ & $y_{i}(2002)^{\mathrm{a}}$ & $\begin{array}{c}y_{i} / y_{D F} \\
(1980)^{\mathrm{b}}\end{array}$ & $\begin{array}{c}y_{i} / y_{D F} \\
(2002)^{\mathrm{b}}\end{array}$ & $\begin{array}{c}\text { Ranking } \\
80 / 2002^{\mathrm{c}}\end{array}$ & $\Delta R^{d}$ & $\begin{array}{c}\text { Crescimento } \\
\text { anual, }(\%)^{\mathrm{e}}\end{array}$ \\
\hline Distrito Federal & 11,91 & 13,82 & 1,00 & 1,00 & $1 / 1$ & 0 & 0,68 \\
São Paulo & 10,57 & 9,59 & 0,89 & 0,69 & $2 / 3$ & -1 & $-0,44$ \\
Rio de Janeiro & 8,52 & 9,68 & 0,72 & 0,70 & $3 / 2$ & 1 & 0,58 \\
Rio Grande do Sul & 7,15 & 8,41 & 0,60 & 0,61 & $4 / 4$ & 0 & 0,74 \\
Santa Catarina & 6,36 & 7,83 & 0,53 & 0,57 & $5 / 5$ & 0 & 0,95 \\
Mato Grosso do Sul & 5,59 & 5,99 & 0,47 & 0,43 & $6 / 9$ & -3 & 0,31 \\
Amazonas & 5,47 & 7,07 & 0,46 & 0,51 & $7 / 6$ & 1 & 1,17 \\
Paraná & 5,28 & 6,96 & 0,44 & 0,50 & $8 / 7$ & 1 & 1,25 \\
Espírito Santo & 5,09 & 6,45 & 0,43 & 0,47 & $9 / 8$ & 1 & 1,07 \\
Minas Gerais & 4,93 & 5,72 & 0,41 & 0,41 & $10 / 10$ & 0 & 0,67 \\
Rondônia & 3,92 & 4,09 & 0,33 & 0,30 & $11 / 14$ & -3 & 0,20 \\
Mato Grosso & 3,76 & 5,72 & 0,32 & 0,41 & $12 / 11$ & 1 & 1,91 \\
Roraima & 3,76 & 3,52 & 0,32 & 0,25 & $13 / 17$ & -4 & $-0,30$ \\
Amapá & 3,27 & 4,42 & 0,28 & 0,32 & $14 / 12$ & 2 & 1,36 \\
Bahia & 3,21 & 3,91 & 0,27 & 0,28 & $15 / 15$ & 0 & 0,89 \\
Pará & 3,21 & 3,28 & 0,27 & 0,24 & $16 / 19$ & -3 & 0,11 \\
Pernambuco & 2,89 & 3,79 & 0,24 & 0,27 & $17 / 16$ & 1 & 1,24 \\
Acre & 2,71 & 3,24 & 0,23 & 0,23 & $18 / 20$ & -2 & 0,81 \\
Sergipe & 2,39 & 4,29 & 0,20 & 0,31 & $19 / 13$ & 6 & 2,65 \\
Alagoas & 2,34 & 2,54 & 0,20 & 0,18 & $20 / 23$ & -3 & 0,37 \\
Rio Grande do Norte & 2,34 & 3,41 & 0,20 & 0,25 & $21 / 18$ & 3 & 1,71 \\
Ceará & 2,04 & 2,64 & 0,17 & 0,19 & $22 / 22$ & 0 & 1,18 \\
Paraíba & 1,65 & 2,80 & 0,14 & 0,20 & $23 / 21$ & 2 & 2,39 \\
Maranhão & 1,48 & 1,65 & 0,12 & 0,12 & $24 / 25$ & -1 & 0,48 \\
Piauí & 1,23 & 1,79 & 0,10 & 0,13 & $25 / 24$ & 1 & 1,69 \\
\hline Fon & & & & & & &
\end{tabular}

Fonte: Elaboração própria.

Notas: Os Estados de Tocantins e Goiás foram excluídos. ${ }^{a}$ Produto Interno Bruto per capita. ${ }^{\mathrm{b}}$ Produto Interno Bruto per capita relativo ao Distrito Federal, $y_{i} / y_{D F}$, sendo $y_{i}$ o PIB per capita da Unidade Federativa i e $y_{D F}$ o PIB per capita do Distrito Federal. ${ }^{\mathrm{c}}$ Ranking por ordem decrescente de PIB per capita. ${ }^{\text {d }}$ Variação de posição - valor positivo significa melhoria de posição. ${ }^{\mathrm{e}}$ Taxa média de crescimento entre 1980 - 2002; calculada pela fórmula $\ln$ (Final) $-\ln ($ Inicial $) / t$, sendo $t$ o número de anos entre a observação inicial e final. Nesse caso, $t=$ 22. 
São Paulo, o Estado mais rico na década de 1980, apresentou uma taxa negativa de crescimento da renda per capita. Como consequência, o gap do PIB per capita em relação ao Distrito Federal aumentou em 20\%, sendo ainda superado pelo Rio de Janeiro, em 2002. Outro Estado com uma relevante elevação do gap em relação ao Distrito é Roraima, que perdeu quatro posições, no período em questão.

Os dados da Tabela 2 também mostram uma elevada desigualdade no nível educacional entre os Estados brasileiros. A diferença de anos de estudo da população com 25 anos ou mais do Distrito Federal e do Piauí, no início do período, chegava a ser de mais de quatro anos.

Tabela 2 - Disparidades no Indicador de Capital Humano: 1981 - 2002

\begin{tabular}{lccccccc}
\hline Unidade Federativa & $H(1981)^{\mathrm{a}}$ & $H(2002)^{\mathrm{a}}$ & $\begin{array}{c}H_{i} / H_{D F} \\
(1981)^{\mathrm{b}}\end{array}$ & $\begin{array}{c}H_{i} / H_{D F} \\
(2002)^{\mathrm{b}}\end{array}$ & $\begin{array}{c}\text { Ranking } \\
81 / 2002^{\mathrm{c}}\end{array}$ & $\Delta R^{d}$ & $\begin{array}{c}\text { Crescimento } \\
\text { anual, }(\%)^{\mathrm{e}}\end{array}$ \\
\hline Distrito Federal & 6.28 & 8.54 & 1.00 & 1.00 & $1 / 1$ & 0 & 1.46 \\
Rio de Janeiro & 5.40 & 7.36 & 0.86 & 0.86 & $2 / 2$ & 0 & 1.47 \\
Amazonas & 4.81 & 6.84 & 0.77 & 0.80 & $3 / 4$ & -1 & 1.68 \\
Roraima & 4.76 & 5.54 & 0.76 & 0.65 & $4 / 16$ & -12 & 0.72 \\
São Paulo & 4.67 & 7.15 & 0.74 & 0.84 & $5 / 3$ & 2 & 2.03 \\
Pará & 4.49 & 6.02 & 0.71 & 0.70 & $6 / 12$ & -6 & 1.40 \\
Rio Grande do Sul & 4.31 & 6.50 & 0.69 & 0.76 & $7 / 7$ & 0 & 1.96 \\
Amapá & 4.16 & 6.68 & 0.66 & 0.78 & $8 / 5$ & 3 & 2.26 \\
Espírito Santo & 3.95 & 6.03 & 0.63 & 0.71 & $9 / 11$ & -2 & 2.01 \\
Santa Catarina & 3.94 & 6.56 & 0.63 & 0.77 & $10 / 6$ & 4 & 2.43 \\
Acre & 3.80 & 6.19 & 0.61 & 0.72 & $11 / 9$ & 2 & 2.32 \\
Mato Grosso do Sul & 3.65 & 6.16 & 0.58 & 0.72 & $12 / 10$ & 2 & 2.49 \\
Minas Gerais & 3.58 & 5.80 & 0.57 & 0.68 & $13 / 15$ & -2 & 2.30 \\
Paraná & 3.44 & 6.33 & 0.55 & 0.74 & $14 / 8$ & 6 & 2.90 \\
Mato Grosso & 3.41 & 5.96 & 0.54 & 0.70 & $15 / 13$ & 2 & 2.66 \\
Rondônia & 3.41 & 5.83 & 0.54 & 0.68 & $16 / 14$ & 1 & 2.55 \\
Pernambuco & 2.86 & 5.14 & 0.46 & 0.60 & $17 / 19$ & -2 & 2.79 \\
Rio Grande do Norte & 2.79 & 5.20 & 0.44 & 0.61 & $18 / 18$ & 0 & 2.96 \\
Paraíba & 2.63 & 4.44 & 0.42 & 0.52 & $19 / 22$ & -3 & 2.49 \\
Bahia & 2.55 & 4.53 & 0.41 & 0.53 & $20 / 21$ & -1 & 2.74 \\
Sergipe & 2.47 & 5.25 & 0.39 & 0.61 & $21 / 17$ & 4 & 3.59 \\
Ceará & 2.27 & 4.62 & 0.36 & 0.54 & $22 / 20$ & 2 & 3.38 \\
Alagoas & 2.12 & 3.98 & 0.34 & 0.47 & $23 / 25$ & -2 & 3.00 \\
Maranhão & 1.96 & 4.14 & 0.31 & 0.48 & $24 / 23$ & 1 & 3.56 \\
Piauí & 1.79 & 4.04 & 0.29 & 0.47 & $25 / 24$ & 1 & 3.88 \\
\hline
\end{tabular}

Fonte: Elaboração própria.

Notas: Os Estados de Tocantins e Goiás foram excluídos. ${ }^{a}$ Anos de estudo das pessoas com 25 anos e mais. ${ }^{\mathrm{b}}$ Anos de estudo das pessoas com 25 anos e mais relativos ao Distrito Federal, $H_{i} / H_{D F}$, sendo $H_{i}$ os anos de estudo da população com 25 anos e mais da Unidade Federativa e $H_{D F}$ OS anos de estudo da população com 25 anos e mais do Distrito Federal. ${ }^{\mathrm{c}}$ Ranking por ordem decrescente de anos de estudo das pessoas com 25 anos e mais. ${ }^{\mathrm{d}}$ Variação de posição - valor positivo significa melhoria de posição. ${ }^{\text {e }}$ Taxa média de crescimento entre 1981 - 2002; calculada pela fórmula $\ln$ (Final) $-\ln$ (Inicial) / $t$, sendo $t$ o número de anos entre a observação inicial e final. Nesse caso, $t=21$. 
Se compararmos os resultados da Tabela 1 com os da Tabela 2, pode-se chegar a algumas conclusões interessantes. Em primeiro lugar, deve-se notar a elevação do gap educacional entre Roraima e o Distrito Federal. O primeiro, no mesmo período analisado, perdeu quatro posições no nível de produto per capita. Sergipe, que quase dobrou os anos de escolaridade da sua população com 25 anos ou mais, apresentou a maior taxa de crescimento do PIB per capita no período. O Estado do Paraná, além de aumentar em praticamente três anos a média de escolaridade da sua população e ganhar seis posições, apresentou uma das maiores taxas de crescimento econômico no período.

Cabe ainda destacar que o índice de correlação de ordem (SPEARMAN) entre as variáveis de capital humano e renda per capita foram altos nos dois períodos. Para o ano de 1980, a correlação encontrada foi de 0,81, enquanto para 2002 esse valor subiu para 0,87 .

A análise conjunta das tabelas permite realçar uma importante conclusão de diversos autores sobre o tema: o capital humano possui papel fundamental na determinação do crescimento econômico. Os Estados que conseguiram melhorar significativamente o nível de escolaridade da sua população foram aqueles que obtiveram melhoras expressivas no nível de produto per capita. Essa conclusão é similar à encontrada por Nakabashi e Salvato (op. cit.), na qual o capital humano é essencial para explicar o diferencial de renda entre os Estados brasileiros. Os autores ainda ressaltam que o diferencial educacional é ainda maior quando se leva em conta a qualidade desse fator.

\subsection{Resultados Econométricos}

\subsubsection{Especificação de MRW}

A análise da Tabela 3 indica que há fortes indícios da presença de heterocedasticidade e autocorrelação de primeira ordem no painel para as duas especificações da função de produção. A multicolinearidade não se mostrou como um problema sério. Dessa forma, a heterocedasticidade e autocorrelação de primeira ordem devem ser consideradas para a estimação dos parâmetros. 
Tabela 3 - Testes de Multicolinearidade, Heterocedasticidade e Autocorrelação no Painel de Dados

\begin{tabular}{lcccccc}
\hline \multirow{2}{*}{ Especificação } & Multicolinearidade ${ }^{(*)}$ & \multicolumn{2}{c}{ Heterocedasticidade $^{(* *)}$} & & \multicolumn{2}{c}{ Autocorrelaçãa $^{(* * *)}$} \\
& FIV & Breusch-Pagan & Prob $>\chi^{2}$ & & Arellano-Bond AR(1) & Prob > z \\
\hline MRW & 1.76 & 48.281 & 0.00 & & -8.37 & 0.00 \\
Mincer & 1.76 & 65.314 & 0.00 & & -8.37 & 0.00 \\
\hline
\end{tabular}

Fonte: Elaboração própria.

$\left({ }^{*}\right)$ Como regra prática, a multicolinearidade é considerada um problema sério se FIV $>10$.

$\left({ }^{* *}\right)$ Hipótese nula: os distúrbios são homocedásticos.

$\left({ }^{* *}\right)$ Hipótese nula: Inexiste autocorrelação de primeira ordem.

O próximo passo para a determinação do melhor método de estimação é examinar se o modelo deveria ser estimado com mínimos quadrados ordinários, efeitos fixos ou efeitos aleatórios. Utilizou-se, então, o teste F e o teste de Hausman (1978).

O teste $\mathrm{F}$ compara o método de efeitos fixos com o método de mínimos quadrados ordinários e testa a hipótese que todas as dummies sejam, conjuntamente, iguais a zero. Os resultados do teste $\mathrm{F}$ mostraram que o método de efeitos fixos é mais apropriado para os Estados brasileiros, no período de 1980-2002 (Tabela 4). O teste de Hausman (ibidem) também aponta para a escolha do método de efeitos fixos como o mais adequado (Tabela 4).

Deve-se, também, considerar a presença da endogeneidade das variáveis explicativas na regressão da equação de crescimento. Dessa forma, foi utilizado o teste de Durbin-Wu-Hausman (DWH). Esse teste define os resíduos da variável endógena como função de todas as variáveis exógenas. Os resultados do teste de DWH, apresentados na Tabela 4, apontam para a presença de endogeneidade nas variáveis de capital físico e humano, indicando a necessidade de inclusão de variáveis instrumentais no modelo.

Diante da presença de endogeneidade, o passo seguinte é estimar o modelo usando mínimos quadrados em dois estágios (MQ2E), efeitos fixos com a inclusão de variáveis instrumentais e mínimos quadrados generalizados em dois estágios (MQG2E). O teste $\mathrm{F}$ e o teste de Hausman (ibidem) são usados novamente para definição do melhor método de estimação. Os resultados desses testes sugerem a utilização de efeitos fixos com a inclusão de variáveis instrumentais, como podemos ver nos resultados da Tabela 4. 
Tabela 4 - Equação de MRW para os Estados Brasileiros (1980-2002)

\begin{tabular}{|c|c|c|c|c|c|c|c|c|}
\hline \multirow{2}{*}{ Variáveis } & \multicolumn{8}{|c|}{ Variável dependente: $\ln$ da renda per capita } \\
\hline & (1) & (2) & (3) & (4) & (5) & $(6)^{\dagger}$ & $(7)^{\dagger}$ & $(8)^{f}$ \\
\hline$L N k_{i t}$ & $\begin{array}{l}0.111 \\
(16.31)^{\star \star *}\end{array}$ & $\begin{array}{l}0.070 \\
(4.64)^{\star * \star}\end{array}$ & $\begin{array}{l}0.091 \\
(6.95)^{\star * \star}\end{array}$ & $\begin{array}{l}0.114 \\
(16.45)^{\star * *}\end{array}$ & $\begin{array}{l}0.153 \\
(4.47)^{\star \star \star}\end{array}$ & $\begin{array}{l}0.157 \\
(7.88)^{\star \star \star}\end{array}$ & $\begin{array}{l}0.083 \\
(7.66)^{\star \star \star}\end{array}$ & $\begin{array}{l}0.111 \\
(4.21)^{\star \star \star}\end{array}$ \\
\hline$L N h_{i t}$ & $\begin{array}{l}1.752 \\
(33.25)^{\star * *}\end{array}$ & $\begin{array}{l}0.244 \\
(3.33)^{* * *}\end{array}$ & $\begin{array}{l}0.477 \\
(6.61)^{\star * *}\end{array}$ & $\begin{array}{l}1.786 \\
(33.31)^{* * *}\end{array}$ & $\begin{array}{l}0.396 \\
(4.19)^{\star \star *}\end{array}$ & $\begin{array}{l}0.691 \\
(7.86)^{\star * *}\end{array}$ & $\begin{array}{l}1.225 \\
(14.20)^{\star * *}\end{array}$ & $\begin{array}{l}1.754 \\
(8.63)^{\star \star *}\end{array}$ \\
\hline$L N n_{i t}$ & $\begin{array}{l}0.017 \\
(0.48)\end{array}$ & $\begin{array}{l}0.158 \\
(6.00)^{\star * *}\end{array}$ & $\begin{array}{l}0.175 \\
(6.36)^{\star * *}\end{array}$ & $\begin{array}{l}0.017 \\
(0.50)\end{array}$ & $\begin{array}{l}0.183 \\
(6.38)^{\star \star \star}\end{array}$ & $\begin{array}{l}0.206 \\
(7.02)^{\star \star \star}\end{array}$ & $\begin{array}{l}0.053 \\
(1.74)^{\star}\end{array}$ & $\begin{array}{l}0.017 \\
(0.13)\end{array}$ \\
\hline$T$ & $\begin{array}{l}-0.036 \\
(-12.46)^{\star * *}\end{array}$ & $\begin{array}{l}0.003 \\
(1.53)\end{array}$ & $\begin{array}{l}-0.002 \\
(-1.03)\end{array}$ & $\begin{array}{l}-0.037 \\
(-12.67)^{\star * *}\end{array}$ & $\begin{array}{l}-0.003 \\
(-0.96)\end{array}$ & $\begin{array}{l}-0.009 \\
(-3.45)^{\star * *}\end{array}$ & $\begin{array}{l}-0.021 \\
(-5.68)^{* * *}\end{array}$ & $\begin{array}{l}-0.036 \\
(-4.83)^{\star * \star}\end{array}$ \\
\hline$C$ & $\begin{array}{l}68.702 \\
(12.02)^{\star \star *}\end{array}$ & $\begin{array}{l}-6.359 \\
(-1.57)\end{array}$ & $\begin{array}{l}3.796 \\
(0.92)\end{array}$ & $\begin{array}{l}70.306 \\
(12.22)\end{array}$ & $\begin{array}{l}4.263 \\
(0.80)\end{array}$ & $\begin{array}{l}15.445 \\
(3.22)^{\star \star \star}\end{array}$ & $\begin{array}{l}40.579 \\
(5.52)^{\star \star \star}\end{array}$ & $\begin{array}{l}68.429 \\
(4.64)^{\star \star \star}\end{array}$ \\
\hline$N$ & 450 & 450 & 450 & 450 & 450 & 450 & 450 & 450 \\
\hline$R^{2}$ (ajustado) & 0.79 & - & - & 0.79 & - & - & 0.66 & - \\
\hline$R^{2}$ (between) & - & 0.59 & 0.69 & - & 0.44 & 0.61 & - & - \\
\hline$R^{2}$ (overall) & - & 0.55 & 0.65 & - & 0.43 & 0.58 & - & - \\
\hline$F^{\mathrm{a}}$ & - & 87.63 & - & - & 74.53 & - & - & 46.26 \\
\hline Prob $>F$ & - & 0.000 & - & - & 0.000 & - & - & 0.000 \\
\hline Hausman b & - & 226.33 & - & - & 89.04 & - & - & - \\
\hline Prob $>\chi^{2}$ & - & 0.00 & - & - & 0.00 & - & - & - \\
\hline Endogeneidade $h_{i t}{ }^{c}$ & - & 19.77 & - & - & - & - & - & - \\
\hline Prob $>F$ & - & 0.00 & - & - & - & - & - & - \\
\hline Endogeneidade $k_{i t}^{c}$ & - & 11.56 & - & - & - & - & - & - \\
\hline Prob $>\mathrm{F}$ & - & 0.00 & - & - & - & - & - & - \\
\hline Teste de Sargan ${ }^{d}$ & - & - & - & - & 3.92 & - & - & - \\
\hline Prob $>\chi^{2}$ & - & - & - & - & 0.42 & - & - & - \\
\hline Teste de Hansen ${ }^{e}$ & - & - & - & - & - & - & - & 22.47 \\
\hline Prob $>\chi^{2}$ & - & - & - & - & - & - & - & 1.000 \\
\hline
\end{tabular}

Fonte: Elaboração do autor.

Notas: Regressões: (1) Mínimos Quadrados Ordinários (OLS). (2) Mínimos Quadrados com Variável Dummy (LSDV). (3) Mínimos Quadrados Generalizados (GLS). (4) Mínimos Quadrados em Dois Estágios (2SLS). (5) Efeitos Fixos com a utilização de variáveis instrumentais. (6) Mínimos Quadrados Generalizados em Dois Estágios (G2SLS). (7) Mínimos Quadrados Generalizados Factível completo - estimador Prais-Winsten. (8) Painel Dinâmico: ArellanoBond.

$L N_{k}$ é o logaritmo da variável consumo de energia elétrica industrial, $L N_{h}$ é o logaritmo da variável anos de estudo da população com 25 anos e mais, $L N_{n}$ é o logaritmo da taxa de crescimento populacional, $t$ é o ano e $C$ é a constante. Em parêntesis as estatísticas $t .{ }^{* * *}$ Significante a $1 \%$; ** Significante a $5 \%$; * Significante a $10 \%$

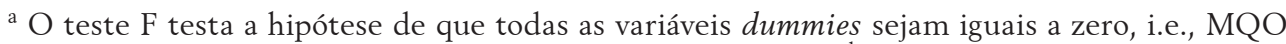
e efeitos fixos são consistentes, mas efeitos fixos é preferível. ${ }^{\mathrm{b}}$ Teste para Efeitos Fixos versus Efeitos Aleatórios: sob $\mathrm{Ho}$, painel com efeitos aleatórios é eficiente. A rejeição de Ho implica que o método de efeitos fixos seja mais eficiente que efeitos aleatórios. ${ }^{\mathrm{c}}$ Teste de Durbin-WuHausman para endogeneidade: sob Ho, a regressão por MQO é consistente, i.e., não há presença de endogeneidade. ${ }^{\text {d }}$ Teste de sobreidentificação das restrições: sob Ho, os instrumentos utilizados são válidos. ${ }^{\text {e }}$ Teste de Sargan não é robusto para painel dinâmico, por isso usamos um teste robusto: Teste de Hansen, sob Ho, os instrumentos utilizados são válidos. ${ }^{\mathrm{f}}$ Instrumentos para as variáveis endógenas $L N k_{i t}$ e $L N h_{i t}$ : 3 defasadas das endógenas e a variável latitude da unidade federativa, além das variáveis exógenas (crescimento populacional e ano). 
Por último, foi feito o teste de Sargan para verificar a validade dos instrumentos utilizados. Sete instrumentos são incluídos no modelo: os valores defasados até a terceira defasagem das proxies para capital físico e capital humano e a latitude. ${ }^{11} \mathrm{O}$ teste de Sargan não rejeita a hipótese de que os instrumentos sejam válidos.

Os resultados das regressões apresentadas na Tabela 4 correspondem à especificação da equação (8) e o nível de significância utilizado foi de 5\%.

Na coluna (1) estão os resultados para a "pooled regression". ${ }^{2}$ No método de estimação com efeitos fixos, o problema da heterogeneidade entre os Estados é resolvido (coluna 2). Os resultados utilizando o método de estimação com efeitos aleatórios são apresentados na coluna (3). Na coluna (4), observam-se os resultados das regressões por MQ2E, enquanto os resultados das regressões do melhor método de estimação - efeitos fixos com a inclusão de variáveis instrumentais - estão descritos na coluna (5). Os resultados da regressão por MQG2E são apresentados na coluna (6) como forma de comparação com os resultados da coluna anterior. Na coluna (7), foi utilizado o estimador de Prais-Winsten que corrige a heterocedasticidade e autocorrelação de primeira ordem no painel de dados. Finalmente, na coluna (8), foi utilizado o estimador de Arellano-Bond para painéis dinâmicos, que é recomendado na presença de variáveis explicativas não exógenas e quando o número de informações no tempo é reduzido. Tal estimador considera uma estimação do modelo escrito em primeira diferença usando o método generalizado dos momentos de Hansen (op. cit.).

Diferentemente do previsto pelo modelo Solow-Swan e dos resultados encontrados por Nakabashi e Salvato (op. cit.) para os Estados brasileiros, a taxa de depreciação efetiva do capital - que tem como proxy a taxa de crescimento da população - tem um impacto positivo sobre o PIB per capita em todos os métodos de estimação utilizados. Adicionalmente, o coeficiente só não é estatisticamente diferente de zero nos resultados apresentados nas colunas (1) e (4). Segundo Figueiredo e Garcia (2003), em um estudo para o período 1960-1990, esse resultado pode ter sido influenciado pelo fato de a renda per capita ser o principal determinante da taxa de migração. Consequentemente, os Estados com maior renda per capita foram aqueles com mais elevada taxa de crescimento populacional e da força de trabalho.

Um dos principais resultados encontrados é que tanto o capital físico quanto o capital humano têm influência positiva sobre o nível de produto per capita e são estatisticamente significativos em todas as regressões. Desse modo, como foram

11 Valor absoluto da latitude dividido por 90 para ficar em uma escala de 0 a 1 - procedimento equivalente ao proposto por Hall e Jones (1999).

12 Na pooled regression, as especificidades de cada Estado não são levadas em consideração. 
utilizados vários métodos para estimação da equação (8), pode-se concluir que os resultados são robustos.

Na coluna (1), os resultados para a "pooled regression" indicam que todas as variáveis são estatisticamente significativas, com exceção da taxa de crescimento populacional. Observa-se que o capital humano possui um impacto muito maior no nível de produto per capita do que o capital físico. Enquanto o aumento de $1 \%$ no estoque de capital físico eleva a renda per capita em $0,11 \%$, no caso do capital humano o mesmo aumento proporcional teria um impacto de $1,75 \%$ na renda per capita.

De acordo com os resultados do método de estimação pelo método de efeitos fixos (coluna (2)), o coeficiente do capital humano sofre uma grande redução. Como sugere Nakabashi e Salvato (op. cit.), uma possível explicação para este fato é que o capital humano é positivamente correlacionado com o nível de tecnologia de cada Estado. Dessa forma, parte do impacto desse fator sobre o nível de produto per capita deriva do impacto indireto gerado pela tecnologia. Assim, quando as especificidades de cada Estado são controladas com a introdução das variáveis dummies, o impacto direto do capital humano sobre o nível de PIB per capita se reduz.

Esse resultado também indica que a relação do capital humano com o nível de renda per capita é bem mais complexa do que aquela apontada pelo modelo estendido de Solow (op. cit.). Ou seja, a sua relação com o nível de tecnologia é fundamental.

O método de estimação pelo método de efeitos aleatórios, que também reconhece a heterogeneidade dos Estados, foi apresentado na coluna (3) como uma forma de comparação com efeitos fixos. Os dois métodos apresentam resultados semelhantes.

Para resolver o problema da endogeneidade das proxies para capital físico e humano, a equação de regressão (8) foi estimada utilizando variáveis instrumentais e os resultados são apresentados na coluna (4). Os resultados das regressões por MQ2E são bastante parecidos com os da regressão de Mínimos Quadrados Ordinários (MQO). Isso é um indicativo de que, apesar de sua existência, o problema da endogeneidade não é grave.

Na coluna (5) estão os resultados pelo método considerado mais adequado pelos testes realizados. Desse modo, vale a pena dar mais atenção a eles. Todas as variáveis são significativas, exceto o tempo e a constante. Como nas demais regressões, o efeito da proxy para capital humano é bastante reduzido quando se controla para as especificidades dos Estados. A elevação de 1\% na quantidade dessa variável eleva 
o PIB per capita em 0,4\%. De qualquer forma, seu impacto é consideravelmente maior do que o do capital físico.

Sendo a média de anos de estudo, no período, de 4,7 anos, um ano de escolaridade corresponde a $21,3 \%$ no total de anos de estudo. Dessa forma, um ano adicional de escola aumenta o PIB per capita em 8,5\%. NAKABASHI (2005, p.68) estimou o retorno de um ano adicional de escola em 9,3\%, ou seja, um efeito bem próximo ao encontrado no presente estudo.

Comparando com os resultados de Lau et al. (op. cit.) e Andrade (op. cit.), o efeito do capital humano no presente estudo é bem menor. Isso ocorre porque nos primeiros, as especificidades de cada Estado não foram controladas e, desse modo, o coeficiente da proxy para capital humano também incorporou esses efeitos.

Os resultados da regressão por MQG2E são apresentados na coluna (6). Suas vantagens sobre o método MQ2E são que ele leva em consideração a possibilidade da existência de correlação entre os resíduos das diferentes equações, com ganho de eficiência na estimação dos coeficientes caso essa correlação seja diferente de zero. Comparando com os resultados da equação (4), constatam-se algumas alterações relevantes, como a perda de importância da variável capital humano e o fato de que a proxy para depreciação efetiva do capital ter ser tornado significativa, além de ter ganho importância. Essas alterações indicam que a correlação contemporânea é importante para não ser considerada.

Na coluna (7), os resultados utilizando o método de Prais-Winsten que corrige a heterocedasticidade e autocorrelação de primeira ordem indicam a maior importância do capital humano em relação ao capital físico. Os resultados são similares aos apresentados na regressão por MQO possivelmente pelo fato de a transformação de Prais-Winsten não levar em consideração a especificidade de cada Estado. A diferença é que todas as variáveis se mostraram estatisticamente significantes ao nível de significância de 10\%.

Finalmente na coluna (8), a estimação usando o estimador de Arellano e Bond (op. cit.) para painéis dinâmicos, recomendado quando temos poucas informações no tempo e presença de variáveis explicativas não estritamente exógenas. Os resultados são semelhantes àqueles já descritos para a coluna (4) que usa o método de mínimos quadrados em dois estágios. Neste caso, usamos o mesmo conjunto de instrumentos. O teste de Hansen ainda mostrou que não se pode rejeitar a hipótese de que o conjunto de variáveis instrumentais utilizadas é válido. 
Uma importante conclusão que podemos aferir através da análise da Tabela 4 é que os impactos do capital humano sobre o nível do PIB per capita são positivos e significativos em todos os casos, além de seu efeito ser maior do que o do capital físico, mesmo quando se controla para as especificidades de cada Estado. Embora estudos anteriores demonstrem que o capital físico tenha uma influência maior sobre o nível de produto, todos são unânimes quanto à grande relevância do capital humano na determinação do PIB per capita dos Estados brasileiros.

\subsubsection{Especificação Minceriana}

$\mathrm{Na}$ Tabela 5, estão descritos os resultados das regressões para os Estados brasileiros no período 1980-2002 seguindo a especificação proposta por Mincer (op. cit.) para a função de produção. Os resultados das regressões apresentadas nessa tabela correspondem à especificação da equação (10).

O mesmo procedimento utilizado na especificação de MRW para a determinação do melhor método de estimação foi utilizado na função de produção minceriana. $\mathrm{O}$ teste $\mathrm{F}$ rejeitou a estimação por MQO em favor da estimação com efeitos fixos. Para as regressões utilizando o método de Dados de Painel, os resultados do teste de Hausman apontaram, novamente, que o método de efeitos fixos é mais apropriado em relação ao de efeitos aleatórios. O teste de Durbin-Wu-Hausman indicou a presença de endogeneidade nas proxies para capital físico e humano, tornando necessária a inclusão de variáveis instrumentais no modelo, como podemos ver nos resultados da Tabela 5 .

Os métodos de estimação com a inclusão de variáveis instrumentais foram refeitos para a especificação proposta por Mincer (ibidem). Mais uma vez, utilizou-se o teste F e de Hausman para a determinação do melhor método. Novamente, os resultados apontaram para a escolha de efeitos fixos com a inclusão de variáveis instrumentais como método mais consistente e eficiente. Adicionalmente, há de se considerar a presença de heterocedasticidade e autocorrelação de primeira ordem no painel. As estimações apresentadas em cada coluna correspondem aos métodos utilizados na Tabela 4. 
Tabela 5 - Equação de Mincer (ibidem) para os Estados Brasileiros (1980-2002)

\begin{tabular}{|c|c|c|c|c|c|c|c|c|}
\hline \multirow{2}{*}{ Variáveis } & \multicolumn{8}{|c|}{ Variável dependente: In da renda per capita } \\
\hline & $(1)$ & $(2)$ & (3) & (4) & (5) & $(6)^{g}$ & $(7)^{\mathrm{g}}$ & $(8)^{g}$ \\
\hline$L N k_{i t}$ & $\begin{array}{l}0.113 \\
(16.93)^{\star * \star}\end{array}$ & $\begin{array}{l}0.072 \\
(4.73)^{\star \star \star}\end{array}$ & $\begin{array}{l}0.091 \\
(6.94)^{\star \star *}\end{array}$ & $\begin{array}{l}0.116 \\
(17.07)^{\star \star \star}\end{array}$ & $\begin{array}{l}0.199 \\
(5.43)^{\star \star *}\end{array}$ & $\begin{array}{l}0.174 \\
(8.52)^{\star \star *}\end{array}$ & $\begin{array}{l}0.092 \\
(8.58)^{\star * *}\end{array}$ & $\begin{array}{l}0.113 \\
(4.44)^{* * *}\end{array}$ \\
\hline$h_{i t}$ & $\begin{array}{l}0.384 \\
(33.98)^{\star \star *}\end{array}$ & $\begin{array}{l}0.071 \\
(3.74)^{\star \star \star}\end{array}$ & $\begin{array}{l}0.130 \\
(7.17)^{\star \star \star}\end{array}$ & $\begin{array}{l}0.394 \\
(34.11)^{\star * *}\end{array}$ & $\begin{array}{l}0.154 \\
(4.64)^{\star \star *}\end{array}$ & $\begin{array}{l}0.235 \\
(8.92)^{\star \star *}\end{array}$ & $\begin{array}{l}0.285 \\
(15.48)^{\star * *}\end{array}$ & $\begin{array}{l}0.383 \\
(8.25)^{* * *}\end{array}$ \\
\hline$L N n_{i t}$ & $\begin{array}{l}0.004 \\
(0.12)\end{array}$ & $\begin{array}{l}0.146 \\
(5.56)^{\star \star *}\end{array}$ & $\begin{array}{l}0.150 \\
(5.53)^{\star \star \star}\end{array}$ & $\begin{array}{l}0.001 \\
(0.04)\end{array}$ & $\begin{array}{l}0.170 \\
(5.74)^{\star * *}\end{array}$ & $\begin{array}{l}0.170 \\
(5.65)^{\star * *}\end{array}$ & $\begin{array}{l}0.054 \\
(1.71)^{*}\end{array}$ & $\begin{array}{l}0.006 \\
(0.05)\end{array}$ \\
\hline$T$ & $\begin{array}{l}-0.035 \\
(-12.50)^{\star * *}\end{array}$ & $\begin{array}{l}0.001 \\
(0.51)\end{array}$ & $\begin{array}{l}-0.005 \\
(-2.20)^{\star *}\end{array}$ & $\begin{array}{l}-0.036 \\
(-12.82)^{\star \star \star}\end{array}$ & $\begin{array}{l}-0.011 \\
(-2.72)^{\star \star *}\end{array}$ & $\begin{array}{l}-0.018 \\
(-5.67)^{\star * *}\end{array}$ & $\begin{array}{l}-0.023 \\
(-6.23)^{\star \star *}\end{array}$ & $\begin{array}{l}-0.035 \\
(-4.49)^{\star * *}\end{array}$ \\
\hline$C$ & $\begin{array}{l}68.278 \\
(12.17)^{\star \star \star}\end{array}$ & $\begin{array}{c}-2.343 \\
(-0.50)\end{array}$ & $\begin{array}{l}9.769 \\
(2.15)^{\star \star}\end{array}$ & $\begin{array}{l}70.593 \\
(12.48)^{\star \star \star}\end{array}$ & $\begin{array}{l}20.547 \\
(2.61)^{\star \star *}\end{array}$ & $\begin{array}{l}34.099 \\
(5.52)^{\star \star *}\end{array}$ & $\begin{array}{l}44.057 \\
(6.10)^{\star \star \star}\end{array}$ & $\begin{array}{l}67.687 \\
(4.35)^{\star \star \star}\end{array}$ \\
\hline$N$ & 450 & 450 & 450 & 450 & 450 & 450 & 450 & 450 \\
\hline$R^{2}$ (adj.) & 0.79 & - & - & 0.79 & - & - & 0.68 & - \\
\hline$R^{2}$ (between) & - & 0.66 & 0.75 & - & 0.51 & 0.71 & - & - \\
\hline $\mathrm{R}^{2}$ (overall) & - & 0.62 & 0.71 & - & 0.49 & 0.68 & - & - \\
\hline $\mathrm{F}^{\mathrm{a}}$ & - & 85.10 & - & - & 64.81 & - & - & 51.72 \\
\hline Prob $>$ F & - & 0.000 & - & - & 0.000 & - & - & 0.000 \\
\hline Hausman $^{\text {b }}$ & - & 89.56 & - & - & 26.92 & - & - & - \\
\hline Prob $>\chi^{2}$ & - & 0.00 & - & - & 0.00 & - & - & - \\
\hline $\mathrm{BOX}-\operatorname{cox} \theta=0^{\mathrm{C}}$ & 14.41 & 5.22 & - & - & - & - & - & - \\
\hline Prob $>\chi^{2}$ & 0.00 & 0.02 & - & - & - & - & - & - \\
\hline $\mathrm{BOX}-\mathrm{COX} \theta=1^{\mathrm{c}^{\prime}}$ & 1.24 & 0.01 & - & - & - & - & - & - \\
\hline Prob $>\chi^{2}$ & 0.26 & 0.93 & - & - & - & - & - & - \\
\hline Endogeneidade $h_{i t}{ }^{d}$ & - & 28.57 & - & - & - & - & - & - \\
\hline Prob $>$ F & - & 0.00 & - & - & - & - & - & - \\
\hline Endogeneidade $\mathrm{k}_{\mathrm{it}}{ }^{\mathrm{d}}$ & - & 13.27 & - & - & - & - & - & - \\
\hline Prob $>$ F & - & 0.00 & - & - & - & - & - & - \\
\hline Teste de Sargan ${ }^{e}$ & - & - & - & - & 8.99 & - & - & - \\
\hline Prob $>\chi^{2}$ & - & - & - & - & 0.06 & - & - & - \\
\hline Teste de Hansen ${ }^{f}$ & - & - & - & - & 8.99 & - & - & 23.18 \\
\hline Prob $>\chi^{2}$ & - & - & - & - & 0.06 & - & - & 1.000 \\
\hline
\end{tabular}

Fonte: Elaboração do autor.

Notas: Regressões: (1) Mínimos Quadrados Ordinários (OLS). (2) Mínimos Quadrados Variável Dummy (LSDV). (3) Mínimos Quadrados Generalizados (GLS). (4) Mínimos Quadrados em Dois Estágios (2SLS). (5) Efeitos Fixos com a utilização de variáveis instrumentais. (6) Mínimos Quadrados Generalizados em Dois Estágios (G2SLS). (7) Mínimos Quadrados Generalizados Factível completo - estimador Prais-Winsten. (8) Painel Dinâmico: Arellano-Bond. $L N_{k}$ é o logaritmo da variável consumo de energia elétrica industrial, $h$ é a variável anos de estudo da população com 25 anos e mais, $L N_{n}$ é o logaritmo da taxa de crescimento populacional, $t$ é o ano e $C$ é a constante. Em parêntesis as estatísticas $t .{ }^{* * *}$ Significante a $1 \%$; ${ }^{* *}$ Significante a $5 \%$; ${ }^{*}$ Significante a $10 \%$.

${ }^{\text {a }} \mathrm{O}$ teste $\mathrm{F}$ testa a hipótese de que todas as variáveis dummies sejam iguais a zero, i.e., MQO e efeitos fixos são consistentes, mas efeitos fixos é preferível. ${ }^{\mathrm{b}}$ Teste para Efeitos Fixos versus Efeitos Aleatórios: sob $\mathrm{Ho}$, painel com efeitos aleatórios é eficiente. A rejeição de $H o$ implica que o método de efeitos fixos seja mais eficiente que efeitos aleatórios. ${ }^{c}$ Teste para determinação da melhor especificação para a função de produção. Sob $H o: \theta=0$. ${ }^{{ }^{\prime}}$ Teste para determinação

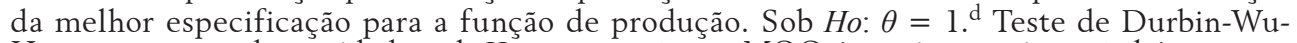
Hausman para endogeneidade: sob $H o$, a regressão por MQO é consistente, i.e., não há presença de endogeneidade. ${ }^{~}$ Teste de sobreidentificação das restrições: sob Ho, os instrumentos utilizados são válidos. ${ }^{\mathrm{f}}$ Teste de Sargan não é robusto para painel dinâmico, por isso usamos um teste robusto: Teste de Hansen, sob $H o$, os instrumentos utilizados são válidos. ${ }^{\mathrm{g}}$ Instrumentos para as variáveis endógenas $L N k_{i t}$ e $L N h_{i t}: 3$ defasadas das endógenas e a variável latitude da unidade federativa, além das variáveis exógenas (crescimento populacional e ano). 
Comparando com os resultados da Tabela 4, o primeiro resultado que chama a atenção é que tanto a magnitude quanto a significância dos coeficientes da proxy para capital físico são praticamente os mesmos, ou seja, o impacto do capital físico sobre o PIB per capita é praticamente o mesmo nas duas especificações, sendo positivo e significativo em todos os casos.

A mesma observação vale para a proxy da depreciação efetiva do capital. A magnitude e a significância dos coeficientes sofrem poucas alterações com a mudança de especificação. Seu impacto é positivo e significativo em todas as estimações, exceto para os resultados da primeira e quarta colunas.

Já a significância dos coeficientes da variável tempo sofre uma alteração maior. $\mathrm{Na}$ Tabela 5, todos os coeficientes são negativos e passam a ser estatisticamente diferentes de zero, exceto para os resultados da estimação apresentados na coluna (2). Essa variável deveria capturar o efeito da tecnologia na evolução do PIB per capita. Desse modo, o sinal negativo reflete a fraca performance dos Estados brasileiros no período de análise.

Focando os resultados da regressão com efeitos fixos e variáveis instrumentais, que são apresentados na coluna (5), notamos que todas as variáveis possuem significância estatística ao nível de $1 \%$. O coeficiente do capital físico se mostrou significativo na determinação do PIB per capita: a elevação em $1 \%$ na acumulação de capital físico eleva o nível do PIB per capita dos Estados brasileiros em, aproximadamente, $0,2 \%$.

Na função de produção minceriana, há um particular interesse no coeficiente da variável de capital humano, isto é, no parâmetro $\varnothing$ da equação (10). De acordo com Ferreira, Issler e Pessôa (op. cit.), ø pode ser interpretado como uma medida da porcentagem de aumento na renda decorrente de um ano adicional de escolaridade. Para os Estados brasileiros, a elevação de um ano de escolaridade eleva a renda em, aproximadamente, $15 \%$, de acordo com os resultados da coluna (5).

A partir de uma amostra ampla de países, Mincer (op. cit.) estimou esse retorno em 10\%. Utilizando a mesma amostra de MRW, Ferreira, Issler e Pessôa (op. cit.) estimaram um retorno de $8 \%$. Considerando o baixo nível de escolaridade nos Estados brasileiros, seria de se esperar uma maior taxa de retorno da educação.

No entanto, é interessante notar a amplitude na taxa de retorno da escolaridade de acordo com as diferentes especificações. O menor retorno é encontrado pelo método de Efeitos Fixos, sendo de apenas 7,1\%, de acordo com os resultados da coluna (2). Já pelo método MQ2E, o retorno é de quase 40\%, como pode ser visto 
na coluna (4). Como ressaltado anteriormente, isso se deve, em boa parte, pelo fato de o método MQ2E não levar em consideração a especificidade de cada estado, sendo o oposto para o método de Efeitos Fixos.

Comparativamente aos resultados do modelo de MRW para os Estados brasileiros, todas as estimações para a especificação minceriana apresentaram coeficiente de determinação mais elevado. Novamente, o impacto do capital humano sobre o nível de produto é superior ao advindo do capital físico. No que tange ao retorno da educação decorrente de um ano adicional de escolaridade, observa-se que aquele obtido por meio da função de produção minceriana é praticamente o dobro daquele que utiliza o modelo neoclássico ampliado de crescimento.

Essas duas especificações foram confrontadas recentemente por Ferreira, Issler e Pessôa (ibidem). Usando o teste Box-Cox, os referidos autores rejeitaram a especificação proposta por MRW em favor da proposta por Mincer (op. cit.) em um painel de 95 países em vários estágios de desenvolvimento para o período 1960-1985.

No presente trabalho, utilizando a amostra para os Estados brasileiros, no período 1980-2002, a aplicação do teste Box-Cox também favorece a especificação minceriana em relação à de $\mathrm{MRW},{ }^{13}$ de acordo com os resultados apresentados na Tabela 5. Este resultado é primordial na determinação do retorno da educação para os Estados brasileiros.

Por fim, não se rejeita a hipótese, como no trabalho de Ferreira, Issler e Pessôa (ibidem), de que a especificação minceriana é mais adequada. Adicionalmente, os resultados apresentam evidências adicionais do papel crucial do capital humano na determinação do nível de produto per capita.

\section{Conclusão}

A importância do capital humano como fator estratégico para o crescimento econômico tem sido amplamente estudada desde o início da década de 1990. No entanto, ainda persistem as discussões sobre os canais pelos quais essa influência se exerce. Ferreira, Issler e Pessoa (ibidem) confrontaram, através de uma amostra para vários países, o modelo proposto por Mankiw, Romer e Weil (op. cit.), em que o capital humano entra na função de produção em nível, com o modelo proposto por Mincer (op. cit.), no qual o capital humano entra na forma exponencial. Por intermédio do

13 Na formulação do teste Box-Cox para os Estados brasileiros não se considerou a variável "tempo". Quando esta variável é incluída no teste, rejeita-se tanto $H o: \theta=0$, como $H o: \theta=1$. 
teste Box-Cox, os referidos autores rejeitaram o modelo neoclássico ampliado de crescimento em favor da especificação minceriana.

O objetivo deste trabalho configurou-se em confrontar essas duas especificações da função de produção para os Estados brasileiros no período 1980-2002. Neste âmbito, também foi utilizado o teste Box-Cox. Adicionalmente, os efeitos do capital humano sobre o PIB per capita foram estimados através do uso de diferentes métodos econométricos para se analisar a robustez dos resultados. Além das tradicionais estimações por Mínimos Quadrados Ordinários (OLS), por Mínimos Quadrados com Variável Dummy (LSDV) e Mínimos Quadrados Generalizados (GLS), foram considerados estimadores de dois estágios com o uso de variáveis instrumentais com o intuito de considerar problemas de endogeneidade. Além disso, na presença de amostra reduzida para informações da série de tempo e variáveis explicativas não exógenas a literatura recomenda o uso dos estimadores de Arellano e Bond (op. cit.) e Arellano e Bover (op. cit.), desenvolvido por Blundell e Bond (op. cit.), usando o algoritmo descrito por Roodman (op. cit.) para painel dinâmico. Não se rejeitou a hipótese de endogeneidade das proxies para capital e trabalho, sendo considerado um conjunto de instrumentos com três defasagens destas variáveis e a variável latitude, além das variáveis exógenas.

Os resultados encontrados no presente estudo sugerem que a especificação proposta por Mincer (op. cit.) é mais adequada que aquela empregada por Mankiw, Romer e Weil (op. cit.). A inclusão do capital humano se mostrou significativa em todas as regressões. O impacto desse fator no PIB per capita é maior que o impacto do capital físico mesmo quando se controla para a especificidade de cada Estado, o que contradiz resultados empíricos de estudos anteriores.

O retorno de um ano adicional de escolaridade, de acordo com a especificação minceriana, situa-se em torno de $15 \%$. Esse valor é maior que o encontrado por Mincer (op. cit.) - 10\% - e quase o dobro do encontrado por Ferreira, Issler e Pessôa (op. cit.) - 8,0\% - para uma amostra de diversos países. Esse resultado não surpreende, visto a baixa dotação do capital humano em relação aos outros fatores de produção no Brasil, o que eleva sua produtividade marginal.

Outro resultado bastante surpreendente é a significância dos fatores capital humano e capital físico em todos os diferentes métodos de estimação e nas diferentes especificações. Mesmo quando considerando a endogeneidade desses fatores e a especificidade de cada Estado, os resultados se sustentaram. Desse modo, o presente estudo, além de apontar que a especificação minceriana é a mais adequada, dá suporte à teoria do capital humano que destaca a importância desse fator na explicação do PIB per capita. 
A redução do efeito do capital humano sobre o PIB per capita, quando se controla para as especificidades de cada Estado, é uma evidência de que esse fator é correlacionado com o nível de tecnologia dos Estados. Assim, uma análise mais aprofundada da relação entre essas duas variáveis é fundamental para se entender a extensão da importância desse fator na determinação do PIB per capita.

\section{Referências}

AGHION, P.; HOWITT, P. A model of growth through creative destruction. Econometrica, v. 60, n. 2, p. 323-351, 1992.

AGUIRRE, A. Uma nota sobre a transformação BOX-COX. Belo Horizonte: UFMG/ Cedeplar, set. 1997, 18p. (Texto para Discussão, 116).

ANDRADE, M. V. Educação e crescimento econômico no Brasil: evidências para os Estados brasileiros: 1970/1995. In: ENCONTRO NACIONAL DE ECONOMIA, 25, 1997, Recife, PE. Anais... São Paulo: ANPEC, 1997. p. 1529-1548.

ARELLANO, M.; BOND, S. Some tests of specification for panel data: Monte Carlo evidence and an application to employment equations. Review of Economic Studies, v. 58, n. 2, p. 277-297, April 1991.

ARELLANO, M.; BOVER, O. Another look at the instrumental variable estimation of error-components models. Journal of Econometrics, v. 68, n. 1, p. 29-51, July 1995.

ARELLANO, M.; HONORE, B. Panel data models: some recent developments. CEMFI, 2000. (Working Paper n. 0016).

AZZONI, C. R. Economic growth and regional income inequality in Brazil. The Annals of Regional Science, v. 35, n. 1, p. 133-152, 2001.

.; MENEZES-FILHO, N.; MENEZES; T., SILVEIRA NETO, R. Geography and regional convergence of income in Brazilian states: 1981-1996. Vienna, Austria: European Regional Science Association, 1999. 23p, p. 196. (ERSA Conference Papers, 99)

BARRO, R.; LEE, J. International Comparison of Educational Attainment. Journal of Monetary Economics, v. 32, n. 3, p. 363-394, 2003.

BARRO, R.; SALA-I-MARTIN, X. Economic growth. McGraw-Hill, 1995.

BENHABIB, J.; SPIEGEL, M. M. Human capital and technology diffusion. New York, NY Federal Reserve Bank of San Francisco, 2002. (Working Paper; 2003-02) Disponível em: < http://www.frbsf.org/publications/economics/papers/2003/ wp03-02bk.pdf $>$.

. The role of human capital in economic development: evidence from aggregate cross-country data. Journal of Monetary Economics, v. 34, n. 2, p. 143-173, 1994. 
BILS, M.; KLENOW, P.J. Does schooling cause growth? American Economic Review, v. 90, n. 5, p. 1160-1183, Dec. 2000.

BLUNDELL, R.; BOND, S. Initial conditions and moment restrictions in dynamic panel data models. Journal of Econometrics, v. 87, p. 115-143, 1998.

BONDE, S. Dynamic panel data models: A guide to micro data methods and practice. London, Institute for Fiscal Studies, 2002. (Working Paper 09/02).

BONELLI, R. Crescimento, desigualdade e educação: notas para uma resenha com referência ao Brasil. Economia Aplicada, v. 6, n. 4, p. 819-873, 2002.

BORENSZTEIN, E.; DE GREGORIO, J.; LEE, J. W. How does foreign direct investment affect economic growth. Journal of International Economics, v. 45, n. 1, p. 115-135, 1998.

COE, D. T.; HELPMAN, E. International R\&D spillovers. European Economic Review, v. 39, n. 5 , p. 859-887, 1995.

.; HOFFMAISTER, A. W. North-South R\&D spillovers. Economic Journal, v. 107, n. 440, p. 134-149, 1997.

CONNOLLY, M. P. The dual nature of trade: measuring its impact on imitation and growth. Journal of Development Economics, v.72, n.1, p.31-55, 2003.

CRAVO, T. A. A importância do capital humano e inovação na convergência real entre países e entre os estados do Brasil. Jan., 2006. 103f. Dissertação (Mestrado em Economia) - Universidade de Coimbra, Portugal.

DAVIDSON, R.; MACKINNON, J. G. Estimation and inference in econometrics. New York: Oxford University Press, 1993.

DIAS, J.; DIAS, M. H. A. Crescimento econômico e as políticas de distribuição de renda e investimento em educação nos estados brasileiros: teoria e análise econométrica. Estudos Econômicos, v. 37, n. 4, p. 701-743, 2007.

; LIMA, F. F. Os efeitos da política educacional no crescimento econômico: teoria e estimativas dinâmicas em painel de dados. Revista de Economia Política, v. 29, n. 3, 2009.

DURLAUF, S. N.; JOHNSON, P. A.; TEMPLE, J. R. W. Growth econometrics. University of Winsconsin, Oct. 2004. (Working Paper, n. 61).

EASTERLY, W.; LEVINE, R. What have we learned from a decade of empirical research on growth? It's not factor accumulation: stylized facts and growth models. The World Bank Economic Review, v. 15, n. 2, p. 177-219, 2001.

FERREIRA, A. H. Convergence in Brazil: recent trends and long-run prospects. Applied Economics, v. 32, n. 4, p. 479-489, Mar. 2000.

. A distribuição interestadual da renda no Brasil, 1950-85. Revista Brasileira de Economia, v.5 0, n. 4, p. 469-485, 1996. 
FERREIRA, P. C.; ISSLER, J. V.; PESSÔA, S. A. Testing production functions used in empirical growth studies. Economics Letters, v. 88, issue 1, p. 29-35, April 2004.

FIGUEIRÊDO, L.; GARCIA, R. A. Impactos de diferentes metodologias para o cálculo da taxa líquida de migração sobre o estudo do crescimento econômico e da distribuição da população dos Estados brasileiros. In: ENCONTRO TRANSDISCIPLINAR ESPAÇO E POPULAÇÃO. Campinas, SP: ABEP/NEPO, 2003.

GREENE, W.H. Econometric analysis. th $^{\text {th }}$ ed. New Jersey: Prentice-Hall, 2001. 1075 p.

HALL, R. E.; JONES, C. I. Why do some countries produce so much more output per worker than others? The Quarterly Journal of Economics, 114, p. 83-116, 1999.

HANSEN, L. Large sample properties of generalized method of moments estimators. Econometrica, v. 50, n. 3, p. 1029-1054, 1982.

HAUSMAN, J.A. Specification tests in econometrics. Econometrica, v. 46, n. 6, p. 1251-1271, Nov. 1978,

Specification and estimation of simultaneous equation models. In: GRILICHES, Zvi; INTRILIGATOR, M. D. (Ed.). Handbook of econometrics. Amsterdam: North Holland, 1983. v. 1.

ISLAM, N. Growth empirics: a panel data approach. The Quarterly Journal of Economics, v. 110, n. 4, p. 1127-1170, 1995.

INSTITUTO DE PESQUISA ECONÔMICA APLICADA. Disponível em: < http:// www.ipea.gov.br>. Acesso em: 30 maio 2007.

JAVORCIK, B. S. Does foreign direct investment increase the productivity of domestic firms? In search of spillovers through backward linkages. American Economic Review, v. 94, n. 3, p. 605-627, 2004.

KELLER, W. How trade patterns and technology flows affect productivity growth. Cambridge, MA.: National Bureau of Economic Research, 1999. 55p. (Working paper n. 6990)

KLENOW, P.J.; RODRÍGUEZ-CLARE, A. The neoclassical revival in growth economics: has it gone too far? In: BERNANKE, B. S.; ROTEMBERG, J. J. (Ed.). NBER macroeconomics annual 1997. Cambridge, MA: MIT press, 1997, p. 83-103.

KRUEGER, A. B.; LINDAHL. Education for growth: why and for whom? Journal of Economic Literature, v. 39, n. 4, p. 1101-1136, 2001.

KYRIACOU, G. Level and growth effects of human capital. C. V. Starr Center for Applied Economics, New York University, 1991. (Working Paper n. 91-26).

LAU, L. J.; JAMISON, D. T.; LIU, S. C.; RIVKIN, S. Education and economic growth: some cross-country evidence from Brazil. Journal of Development Economics, v. 41, n. 1, p. 45-70, June 1993. 
LUCAS, R. E. Jr. On the mechanics of economic development. Journal of Monetary Economics, v. 22, n. 1, p. 3-42, 1988.

MANKIW, N. G.; ROMER, D.; WEIL, D. A contribution to the empirics of economic growth. The Quarterly Journal of Economics, v. 107, n. 2, p. 407- 437, 1992.

MINCER, J. Schooling, experience, and earnings. New York: Columbia University Press, 1974.

NAKABASHI, L. Três ensaios sobre capital humano e renda por trabalhador. 2005. 145p. Tese (Doutorado) - Centro de Desenvolvimento e Planejamento Regional (CEDEPLAR), Universidade Federal de Minas Gerais (UFMG).

NAKABASHI, L.; SALVATO, M. A. Human capital quality in the Brazilian states. Revista Economia, May / Aug. 2007.

NAKABASHI, L.; FIGUEIREDO, L. Mensurando os impactos diretos e indiretos do capital humano sobre o crescimento. Economia Aplicada, v. 12, n. 1, p. 151-171, 2008.

NELSON, R. R.; PHELPS, E. S. Investment in humans, technological diffusion, and economic growth. The American Economic Review, v. 56, n. 2, p. 69-75, 1966.

PORTUGAL, M. S.; SOUZA, N.J . Fatores de crescimento da região Sul, 1960/1995. Economia Aplicada, v. 3, n. 4, p. 577-613, 1999.

PRITCHETT, L. Where has all the education gone? The World Bank Economic Review, v. 15, n. 3, p. 367-391, 2001.

ROMER, P. Endogenous technological change. The Journal of Political Economy, v. 98, n. 5, p. 71-102, 1990a.

. Human capital and growth: theory and evidence. Carnegie-Rochester Conference Series on Public Policy, n.32, p.251-286, 1990 b.

. Idea gaps and object gaps in economic development. Journal of Monetary Economics, v. 32, n. 3, p. 543-573, 1993.

ROODMAN, D. How to do xtabond2: an introduction to "difference" and "system" GMM in Stata. Center for Global Development, Washington, 2006. (Working Paper 103).

SACHS, J. D.; WARNER, A. M. Fundamental sources of long-run growth. The American Economic Review, v. 87, n. 2, p. 184-188, 1997.

SCHULTZ, T. W. Reflections on investment in man. The Journal of Political Economy, v. 70, n. 5, p. 1-8, 1962.

SOLOW, R. M. A contribution to the theory of economic growth. The Quarterly Journal of Economics, v. 70, n. 1, p. 65-94, 1956.

SWAN, T. W. Economic growth and capital accumulation. The Economic Record, p. 334-361, 1956. 
TEMPLE, J. R. W. A positive effect of human capital on growth. Economic Letters, v. 65 , n. 1, p. 131-134, 1999.

TROSTEL, P.A. Returns to scale in producing human capital from schooling. Oxford Economic Papers, 56, p. 461-484, 2004.

$\mathrm{XU}, \mathrm{B}$. Multinational enterprises, technology diffusion, and host country productivity growth. Journal of Development Economics, v. 62, n. 2, p. 477-493, Aug. 2000 . 